\title{
Analysis of different aspects by flexible AC transmission system (FACTS) and distributed-FACTS (D-FACTS) devices on IEEE 14, 30 and 57 bus system
}

\author{
Rizwana Khokhar ${ }^{1}$, Mahendra Lalwani ${ }^{2}$ \\ Department of Electrical Engineering, RTU, Kota, India \\ ${ }^{1}$ rizwanakhokhar941@gmail.com, ${ }^{2}$ mlalwani@rtu.ac.in
}

\begin{abstract}
A electric power system have numerous components utilized in generation, transmission and distribution systems; due to its complex structure a major issue of stability, frequency maintain, power instability in tie-lines and cascading failures exists. To deal with these problems, power electronics based devices: flexible AC transmission system (FACTS) and distributed-FACTS (D-FACTS) devices are placed on optimal location. This paper represents load flow methods: Newton-Raphson method, GaussSeidel method, Fast-Decoupled method, FACTS devices (static synchronous series compensation, unified power flow controller) and D-FACTS devices, used for calculating different line parameter for IEEE 14, 30 and 57 bus system. These methods have varying qualities: convergence, accuracy, reliability, stability etc. The simulation outcomes show comparative analysis of active power, reactive power under steady state condition through different IEEE bus system.
\end{abstract}

Keyword - Flexible AC transmission system (FACTS), distributed flexible AC transmission system (DFACTS), static synchronous series compensation (SSSC), unified power flow controller (UPFC)

\section{INTRODUCTION}

Modern power systems should be necessarily smart, statically, dynamically controllable and energy efficient. The load flow analysis is simple computational procedure for steady state operating condition on power flow system analysis [1]. There is a linear relationship consisting of magnitude at bus voltage, phase angle, true and imaginary power on transmission line. Present power systems are more complex with numerous problems, to diminish these problems, diverse power electronics devices are used [2].

Load flow is improving static nature of electric power system and has three methods: Newton-Raphson (NR) method, Gauss-Seidel (G-S) method and Fast-Decoupled (F-D) method. These methods are more calculative and take very long time for solving power equation. These problems can be enhanced by power electronics based devices i.e. FACTS (i.e. SSSC, UPFC) and D-FACTS. SSSC is energy observing or storing device to boost the power system dynamic nature, reduce voltage drop, independent to control system voltage and improve system performance [3, 4]. UPFC is synchronous voltage device and it is efficient of performing the power flow in a bi-directional way, maintains well regulated DC voltage \& individually controls on all the line parameter (i.e. voltage, current, apparent power) [5].

This paper presents load flow methods implemented to find different line parameter for IEEE 14, 30 and 57 bus systems. The load flow methods include: Newton-Raphson method, Gauss-Seidel method, Fast-Decoupled method, FACTS devices and D-FACTS devices. The methods are evaluated such as convergence, accuracy, reliability, and stability. A comparative study of true power, imaginary power under steady state condition is performed using simulation.

The description of this paper is classified in the following section: section II provides problem description of power flow, overview of the available load flow methodologies, followed by FACT, D-FACTS devices present in section III. Section IV designates modelling of numerous type of IEEE bus system by the implementation of the methods: G-S method, N-R method, F-D method, UPFC, SSSC \& implementation of DFACTS devices and MATLAB based simulation results. The overall conclusion of this paper is presented in section V.

\section{FORMULATION OF PROBLEM}

An electrical phase shift is increasing with distance and power flow along with transmission line. The basic problem is controllability or stability; to resolve these problems FACTS, D-FACTS devices are implemented on IEEE bus system [6-8].

Power flow equations are non-linear, it cannot be resolved analytically, so a numeric iterative algorithm is mandatory to explain these equations. This paper proceeds as follows: 
- Create a bus admittance matrix Y-bus for the power system,

- A primary approximation for the voltages (both magnitude and phase angle) at IEEE bus systems,

- Substitute it in the power flow equation and determine the deviations,

- Update the estimated voltages based on N-R, G-S and F-D method,

- Implement the FACTS and D-FACTS devices on IEEE 14, 30 and 57 bus systems. The FACTS and DFACTS devices are used to provide controllability and stability.

The elementary equation for power-flow analysis is derived from the nodal analysis equations for the power system [9].

$$
I_{i}=\sum_{j=1}^{n} Y_{i j} V_{j}
$$

where $Y_{i j}$ is the admittance of line between $i^{\text {th }}$ and $j^{\text {th }}$ bus. Apparent power injected at bus ' $i$ ' is given by,

$$
\begin{aligned}
& S_{i}=P_{i}+j Q_{i}=V_{i} I_{i}{ }^{*} \\
& S_{i}=P_{i}+j Q_{i}=\left|V_{j}\right| e_{j} \delta_{j}\left[\Sigma\left|Y_{i j}\right|\left|V_{j}\right| e_{j}\left(\delta_{j}+\theta_{i j}\right)_{n j=1}\right]
\end{aligned}
$$

here $P_{i}$ and $Q_{i}$ are true and imaginary power at $i^{\text {th }}$ bus, $\delta_{j}$ voltage angle of $i^{\text {th }}$ bus, $\theta_{i j}$ angle of $Y_{i j}$ element of $Y$ bus. Above equation is known as the load flow equation to update voltage magnitudes and angle with growth rate $r$ [10]:

$$
|V|_{(r+1)}=|V|_{r}+|\Delta V|_{r} \text { where }(r+1)=r+\Delta r
$$

\section{EXPLANATION OF APPLIED METHODOLOGIES}

Load flow analysis is iterative and time taking approaches. To solve this analysis, linear equations are required. Different methods are available to solve these iterations:

\section{A. Gauss-Seidel (G-S) Method}

It is an iterative method and has a set of values of the unknown quantities. The process to solve all the identified and real quantities diminishes a pre-specified value to occur. In the G-S load flow, the initial voltage of $i^{\text {th }}$ bus is given by [11-14]. Knowing the real and reactive power injected at any bus as:

$$
\begin{gathered}
P_{i}-j Q_{i}=V_{i}{ }^{*} I_{i}=V_{i} I_{i}{ }^{*}=\sum_{j=1}^{n} Y_{i j} V_{i} \\
V_{i}=\frac{1}{Y_{i i}}\left[\frac{P_{i}-j Q_{i}}{V_{i}{ }^{*}}-\sum_{j=1}^{n} Y_{i j} V_{i}\right]
\end{gathered}
$$

The updated voltage at bus after iteration is:

$$
V_{i}(\mathrm{acc})=V_{i}(\mathrm{acc})^{(\mathrm{k}-1)}+\lambda\left(V_{i}^{(\mathrm{k})}-V_{i}(\mathrm{acc})^{(\mathrm{k}-1)}\right)
$$

where $V_{i}$ (acc) is acceleration factor and $\mathrm{k}$ is acceleration factor constant. The value of $\lambda$ has to be below 2.0 for the convergence to occur.

B. Newton-Raphson (N-R) Method

$\mathrm{N}-\mathrm{R}$ load flow is solved for non-linear equation at each iteration, a jacobian matrix solves for the modification in the bus system [15].

$$
\left[\begin{array}{c}
\Delta P \\
\Delta Q
\end{array}\right]=[J]\left[\begin{array}{l}
\Delta \delta \\
\Delta V
\end{array}\right] ; \quad[J]=\left[\begin{array}{ll}
J_{1} & J_{2} \\
J_{3} & J_{4}
\end{array}\right]
$$

\section{Fast-Decoupled (F-D) Method}

A significant and beneficial property of power system is that the transformation in active power is primarily governed by the changes in the voltage angle, but not voltage magnitude. Due to the changes, in the imaginary power are primarily influenced by the changes in voltage magnitudes, but not in the voltage angles $[16,17]$.

$$
\begin{gathered}
\frac{\partial Q_{i}}{\partial \theta_{i}} \approx 0 \text { and } \frac{\partial Q_{j}}{\partial \theta_{j}} \approx 0 \geq J_{3} \approx 0, \frac{\partial P_{i}}{\partial V_{i}} \approx 0 \text { and } \frac{\partial P_{j}}{\partial V_{j}} \approx 0 \geq J_{2} \approx 0 \\
{\left[\begin{array}{l}
\Delta P \\
\Delta Q
\end{array}\right]=[J]\left[\begin{array}{c}
\Delta \delta \\
\Delta V
\end{array}\right] ;[J]=\left[\begin{array}{cc}
J_{1} & 0 \\
0 & J_{4}
\end{array}\right]}
\end{gathered}
$$

It gives faster convergence in comparison to $\mathrm{N}-\mathrm{R}$ method but will give approximated result.

D. Flexible AC transmission system (FACTS) 
FACTS are power electronics based devices which are used for enhancing system utilization and power transfer capacity in addition to stability, security \& reliability of interconnected power system. Use of high speed power electronics controllers give chances for increasing efficiency and greater control that flows in the recommended transmission system [18-21]. Table 1 elaborates the different qualities of FACTS devices, used in this paper.

TABLE I. Description of FACTS device (i.e. SSSC, UPFC)

\begin{tabular}{|l|l|l|l|l|l|l|}
\hline Parameter & Type & Control & $\begin{array}{l}\text { Load } \\
\text { Control }\end{array}$ & $\begin{array}{l}\text { Voltage } \\
\text { Control }\end{array}$ & $\begin{array}{l}\text { Transient } \\
\text { Stability }\end{array}$ & $\begin{array}{l}\text { Oscillation } \\
\text { Damping }\end{array}$ \\
\hline SSSC [16] & Series & Power & High & High & High & Average \\
\hline UPFC [15] & Shunt \& Series & Power \& Voltage & High & Low & High & High \\
\hline
\end{tabular}

\section{E. Distributed flexible AC transmission system (D-FACTS)}

D-FACTS device provides purely reactive/capacitive compensation. The concept of distributed series impedance can be realized for variable line impedance. Control active power flow is used for illustrating the feasibility of D-FACTS, it can be configured to operate autonomous during certain conditions to communicate wireless, allowing them to receive commands for impedance injection changes [22, 23].

D-FACTS devices are power flow controller devices which are light-weight, small in size. A D-FACTS device changes the effective line impedance by producing a voltage drop across the line current [24].

\section{Simulation Model, Result ANd Discussion}

The finest position for reactive power compensation static voltage stability margin is the feeblest bus of the system. The feeblest bus of the system could be found using tangent vector study. The feeblest bus is defined as the adjacent to experiencing a voltage collapse.

The simulation result are shown in various parts: Part (i) shows simulation results of IEEE 14 bus compression graph with voltage, current, true and reactive power with FACTS and D-FACTS devices; Part (ii) presents voltage, current and power vs. bus number graph for 30 bus system and Part (iii) presents different graphs by using FACTS, D-FACTS device on 57 bus system.

It can be clearly observed through graphs that FACTS and D-FACTS devices remarkably improve the performance of bus system.

\section{(i). 14 Bus system}

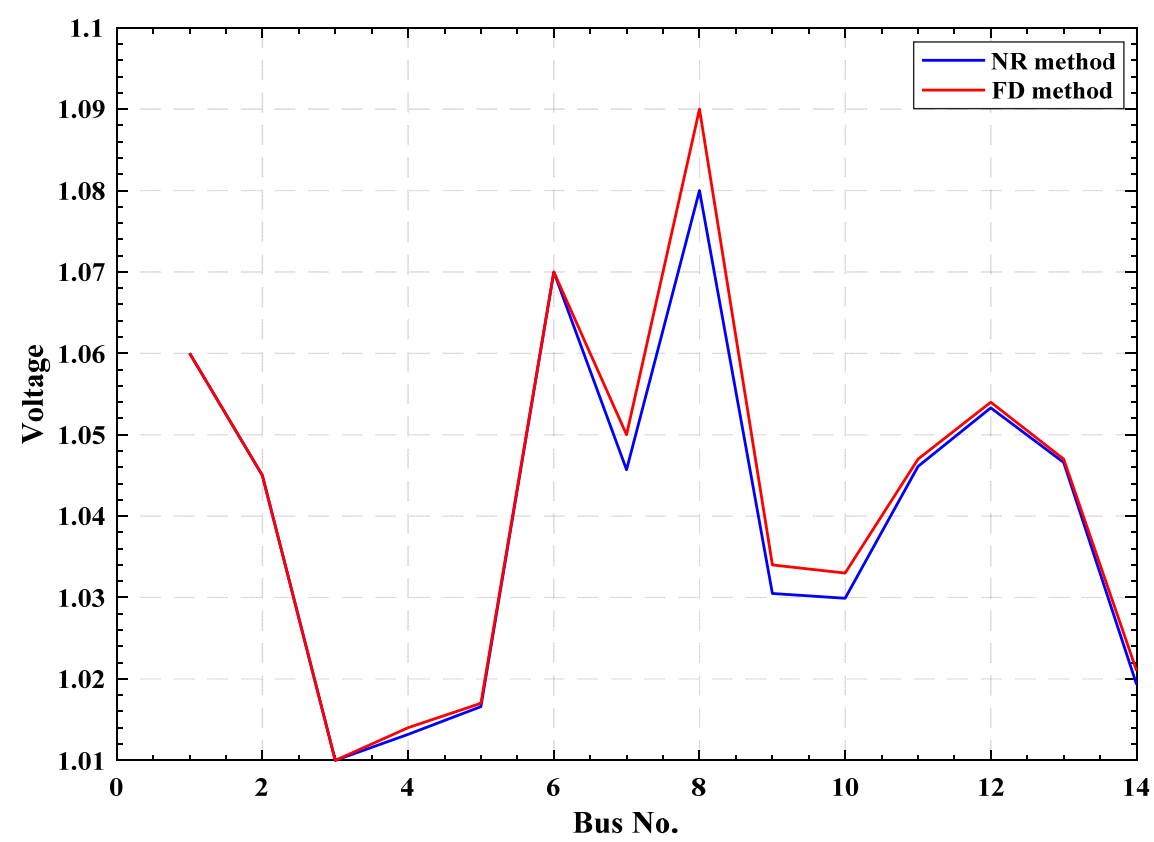

Fig. 1 Voltage comparison between N-R and F-D methods 


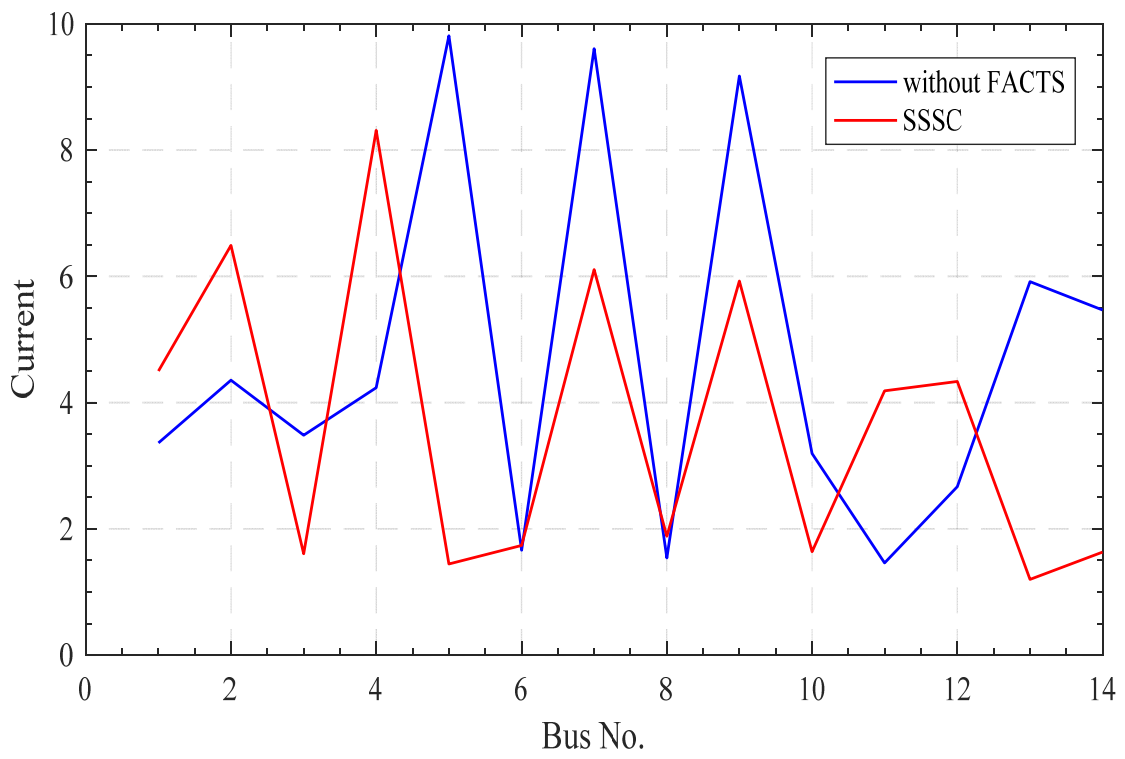

Fig. 2 Current comparison between SSSC and without FACTS Devices

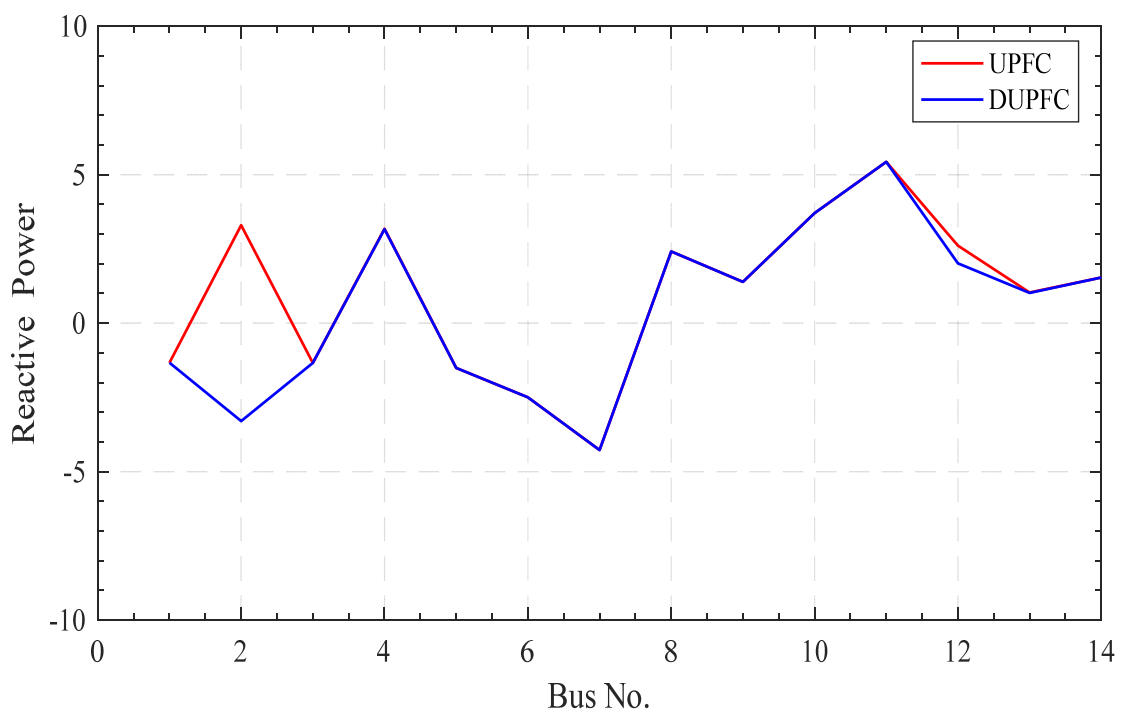

Fig. 3 Reactive power comparison between UPFC and DUPFC

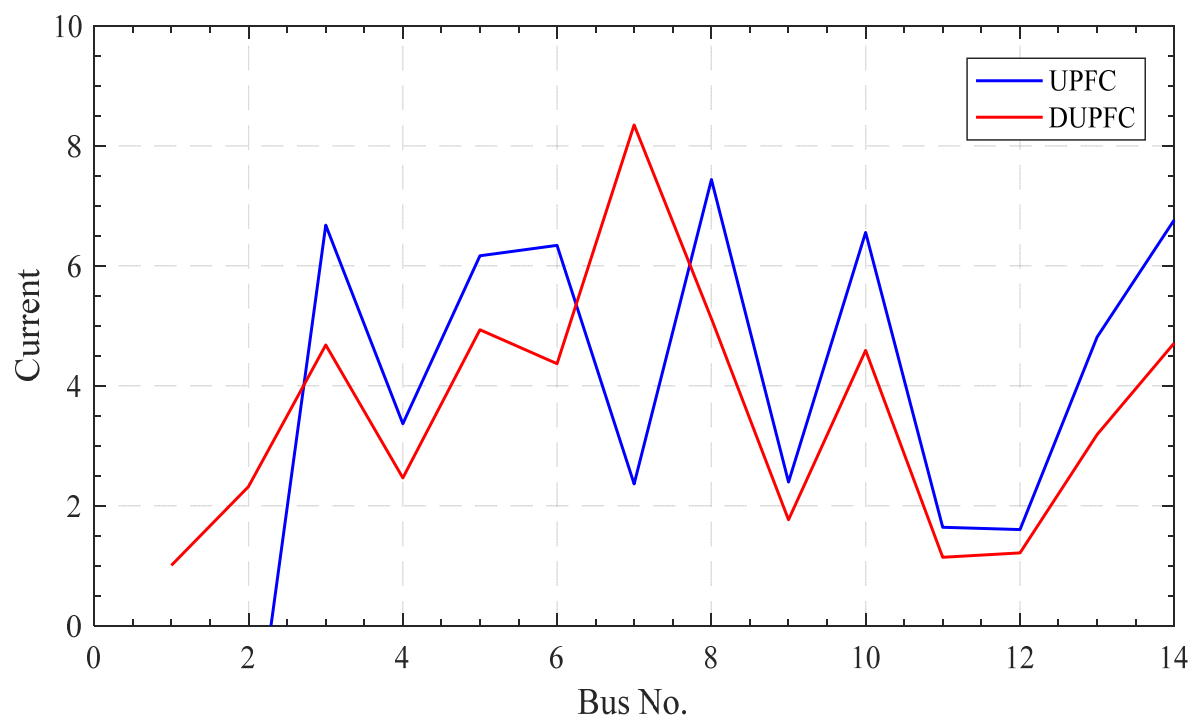

Fig. 4 Current comparison between UPFC and DUPFC 


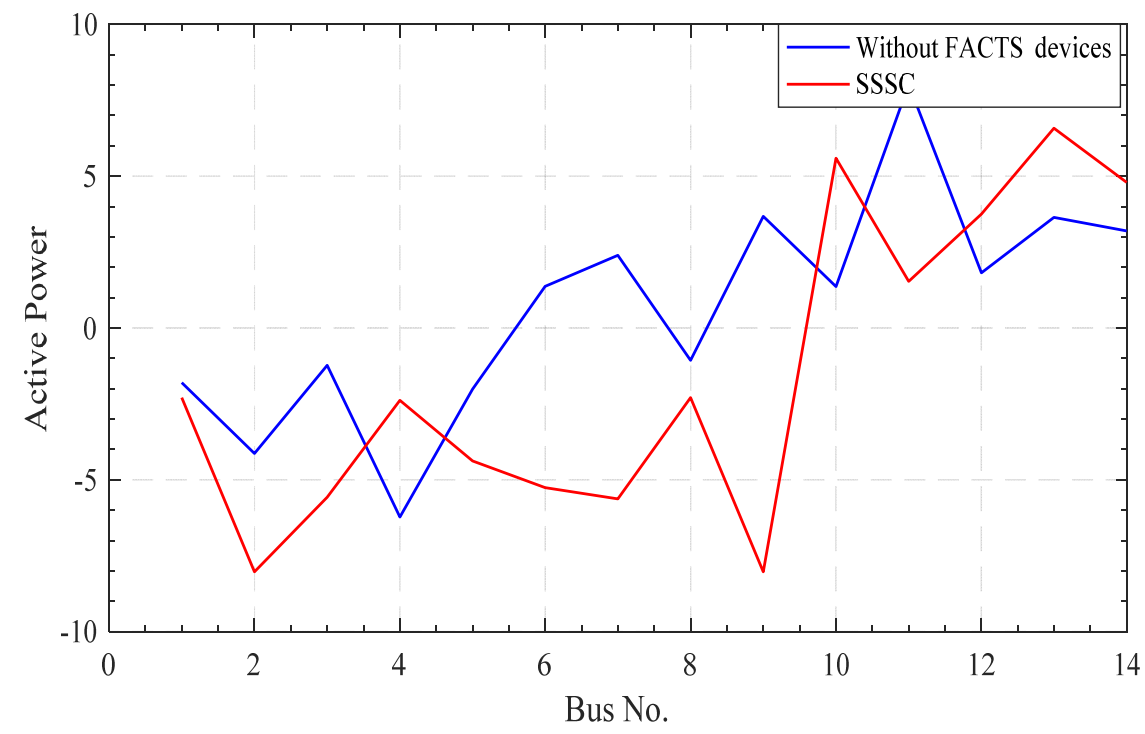

Fig. 5 Active power comparison between SSSC and without FACTS Devices

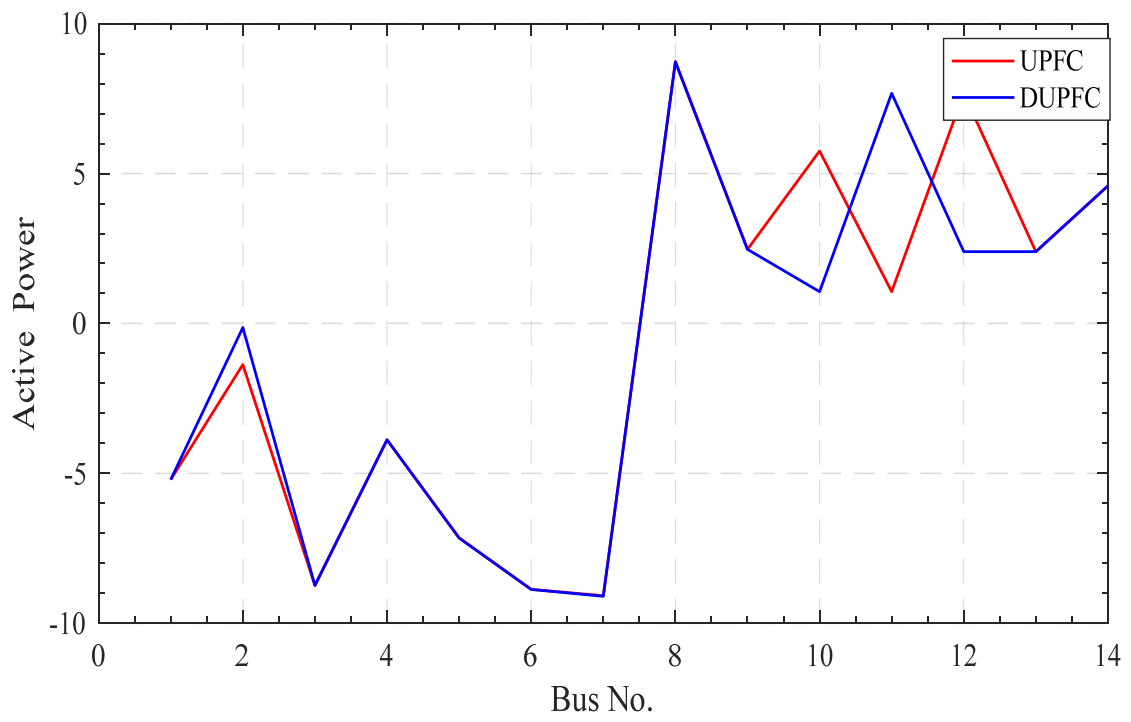

Fig. 6 Active power comparison between UPFC and DUPFC

\section{(ii). 30 Bus system}

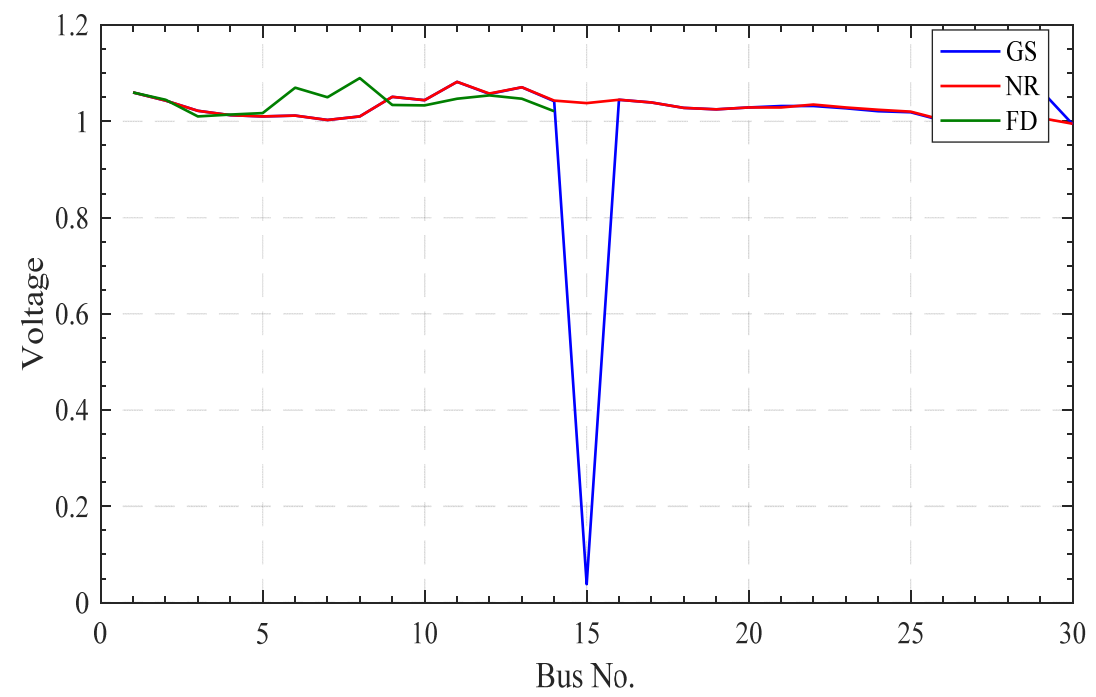

Fig. 7 Voltage comparison between G-S, N-R and F-D method 


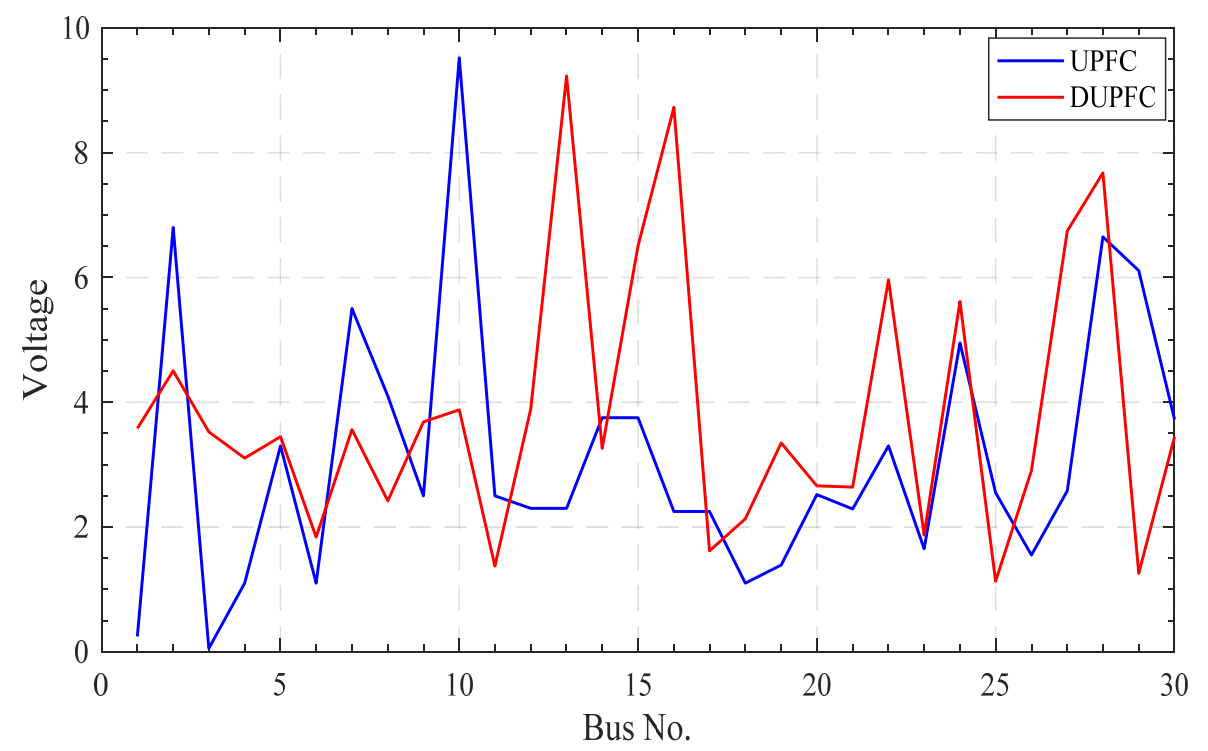

Fig. 8 Voltage comparison between UPFC and DUPFC

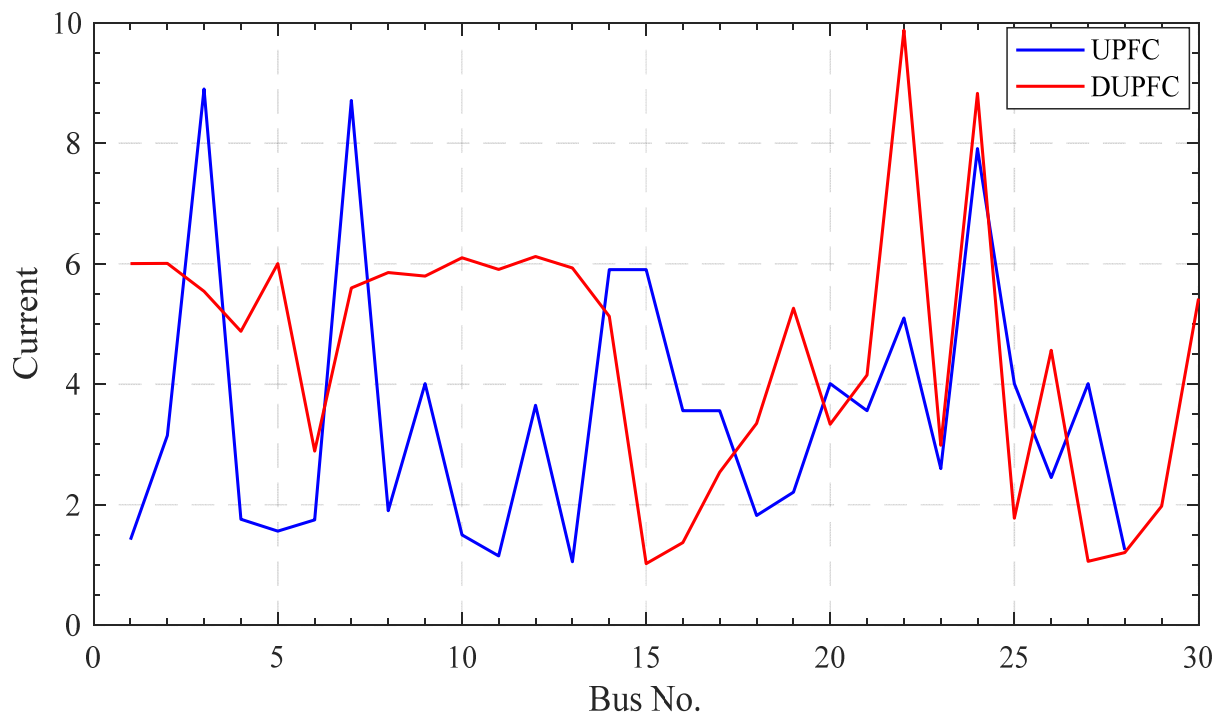

Fig. 9 Current comparison between UPFC and DUPFC

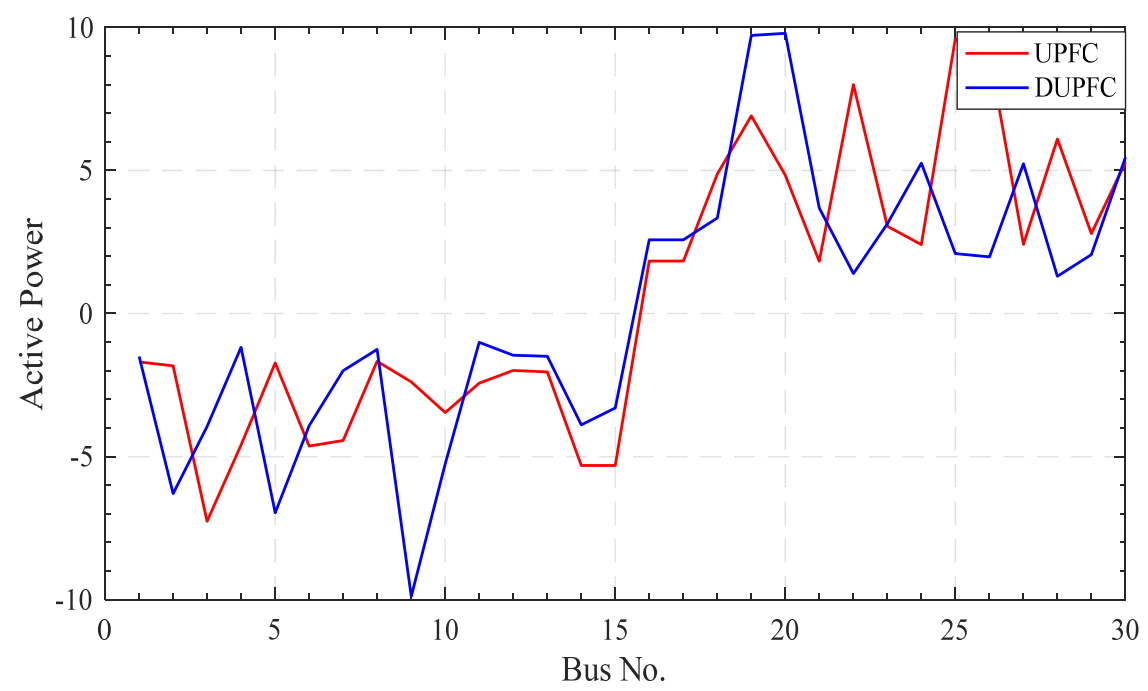

Fig. 10 Active power comparison between UPFC and DUPFC 
(iii). 57 Bus system

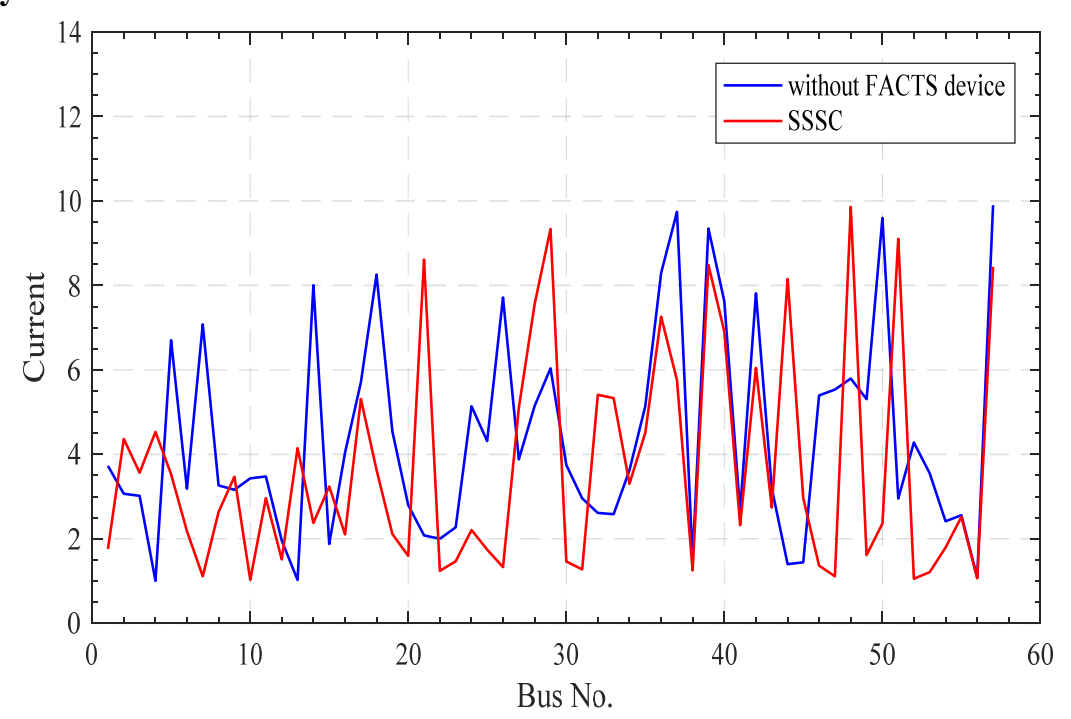

Fig. 11 Current comparison between SSSC and without FACTS devices

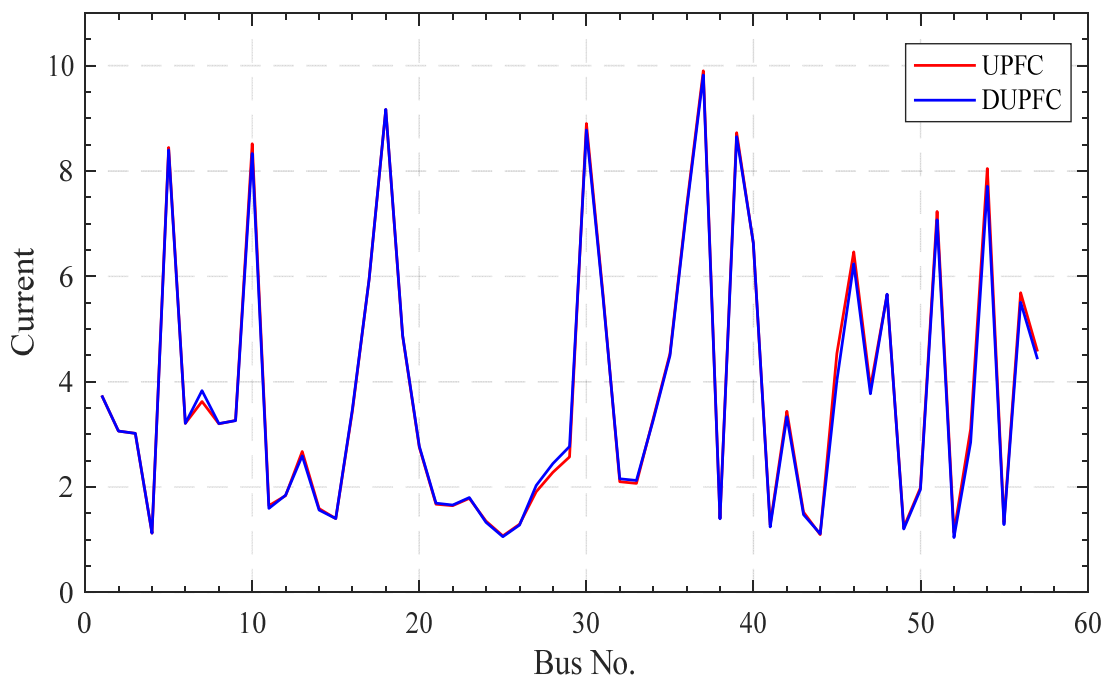

Fig. 12 Current comparison between UPFC and DUPFC

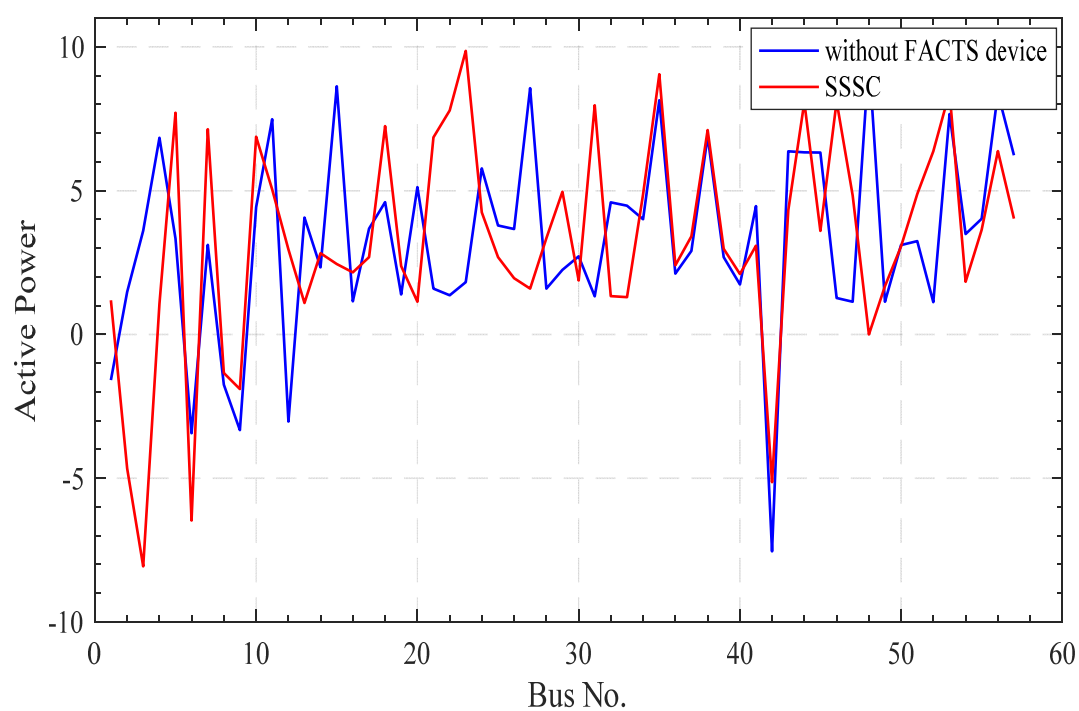

Fig. 13 Active power comparison between SSSC and without FACTS device 


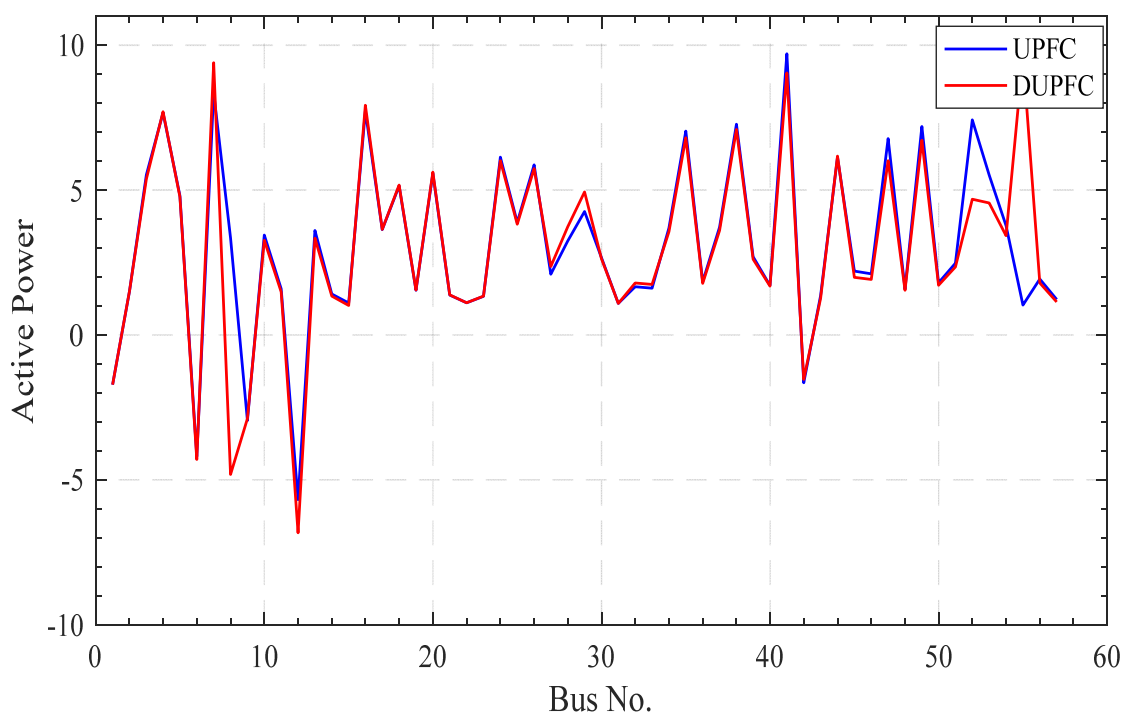

Fig. 14 Active power comparison between UPFC and DUPFC

\section{Conclusion}

The load flow analysis is discussed in presented work for the Newton-Raphson method and Gauss-Seidel method, where Gauss-Seidel method produces better results within less number of iterations. By using Fast Decoupled method, the same results are obtained as obtained by Newton-Raphson method at the least number of iteration. Moreover FACTS devices, UPFC \& SSSC further improve the result, voltage magnitude, angle, active power \& reactive power and also, power flow can also be increased by using D-FACTS devices.

As shown by graphs, required number of iteration gets reduced by applying in various FACTS, SSSC, UPFC and D-FACTS devices, and the following objectives are achieved: upgraded voltage across various bus systems, amplified power transfer capability. After D-FACTS devices are installed in certain fixed locations, their control objectives can easily be changed to target other lines flows. Thus, D-FACTS device can provide versatile control for power systems, which could be a competent research field in future.

\section{REFERENCES}

[1] Saadat, H.: Power System Analysis. Tata McGraw Hill (2002).

[2] Jamali, S., Javdan, M.R., Shateri, H., Ghorbani, M.: Load Flow Method for Distribution Network Design by Considering Committed Loads, Universities Power Engineering Conference, Cardiff, Wales, vol. 41, pp. 856-860 (2006).

[3] Wadhwa, C.L.: Electrical Power System. 6th Edition, New Age International Publishers (2010).

[4] Srikant, P., Rajendra, O., Yesuraj, A., Tilak, M., Raja K.: Load Flow Analysis of IEEE 14 Bus System using MATLAB. International Journal of Engineering Research \& Technology, vol. 2, pp. 149-155 (2013).

[5] Kanti, D.K., Dharamjit, S.: Load Flow Analysis on IEEE 30 Bus System. International Journal of Scientific and Research Publications, vol. 2, pp.1-6 (2012).

[6] Bhuyan, S., Hazarika, A., Baradalai, A.: Power Flow Analysis on IEEE 57 Bus System using MATLAB. International Journal of Engineering Research \& Technology vol. 3, pp. 161-171 (2014).

[7] Kothari, D.P., Nagrath, I.J.: Modern Power System Analysis, 4th Edition, McGraw Hill (2011).

[8] Wang, X.F., Song, Y., Irving, M.: Modern Power Systems Analysis. 2008 Education Springer, New York, USA (2008).

[9] Deng, Y., Venayagamoorthy, G.K., Harley, R.G.: Optimal Allocation of Power Routers in a STATCOM Installed Electric Grid with High Penetration of Wind Energy, Power Systems Conference (PSC) Clemson University, USA, pp. 1-6 (2015).

[10] Hingorani, N.G., Gyugyi L.: Understanding FACTS Concepts and Technology of Flexible AC Transmission Systems. IEEE Press New York, vol. 2 (2010).

[11] Sedghi, M., Aliakbar, M., Golkar, S.: Analysis and Comparison of Load Flow Method for Distribution Networks Considering Distributed Generation. International Journal of Smart Electrical Engineering, vol. 1, pp. 27-31 (2012).

[12] Papaefthymiou, G., Lahaye, D., Vuik, C., Sluis, L.: Towards Faster Solution of Large Power Flow Problems. IEEE Transactions on Power Systems, vol. 28, pp. 4918-4925 (2013).

[13] Kundur, P.: Power System Stability and Control. McGraw-Hill (1993).

[14] Jiang, X., Chow, J.H., Edris, A., Fardanes, B., Uzunovic, E.: Transfer Path Stability Enhancement by Voltage-Sourced Converter Based FACTS Controllers. IEEE Transactions on Power Delivery, Vol. 25, pp. 1019-1025 (2010).

[15] Gupta, V., Tiwari, R., Niazi K.R.: Optimal Location of FACTS Devices for Improving Performance of Power Systems. IEEE Power and Energy Society General Meeting, pp. 1-8 (2012).

[16] Zellagui, M.: Impacts of FACTS on the Performances of Protection Systems Applied to the Electric Transmission Network in Algeria. M.S. Thesis, Department Electronics Technology, Batna University, Algeria (2014).

[17] Ghahremani, E., Kamwa, I.: Optimal Placement of Multiple-Type FACTS Devices to Maximize Power System Load Ability using a Generic Graphical User Interface. IEEE Transactions on Power System, Vol. 28, pp. 3621-3628 (2013).

[18] Ahmed, A.H.: STATCOM versus SSSC for power system stabilization. IEEE Transaction on Electrical and Electronics Engineering, vol. 12, pp. 474-483 (2017).

[19] Mathad, V.G., Ronad, B.F., Jangamshetti, S.H.: Review on Comparison of FACTS Controllers for Power System Stability Enhancement. International Journal of Scientific and Research Publications, vol. 3, pp. 1-4 (2013).

[20] Sharma, N.K., Jagtap, P.P.: Modelling and Application of Unified Power Flow Controller (UPFC). 3rd International Conference on 
Emerging Trends in Engineering and Technology (ICETET), Goa, India,vol. 5, pp. 350-355 (2010).

[21] Kumar, N.A., Rathinakumar, M., Yogesh, M., Dinesh, J.: Comparative Study on The Effectiveness of TCSC and UPFC FACTS Controllers, International Journal of Computer Applications, vol. 67, pp. 1-5 (2013).

[22] Benaissa, M., Hadjeri, S., Zidi, S.A.: Impact of PSS and SVC on the Power System Transient Stability. Advances in Science, Technology and Engineering Systems Journal, vol. 2, pp. 562-568 (2017).

[23] Basavaraj, B., Basangouda, R., Suresh. J.: Transmission Loss Minimization using UPFC. International Journal of Modern Engineering Research (IJMER), vol. 2, pp. 3602-3606 (2012).

[24] Liu, L., Li, H., Xue, Y., Liu, W.: Reactive power compensation and optimization strategy for grid-interactive cascaded photovoltaic systems. IEEE Transaction on Power Electronics, vol. 30, pp. 188-202 (2015).

\section{AUTHOR PROFILE}

Dr. Mahendra Lalwani is currently working as an Associate Professor in the Department of Electrical Engineering at the Rajasthan Technical University, Kota, India. He has authored many books and research paper in Power System, Power Electronics, and Renewable Energy.

Rizwana Khokhar is M. Tech. Scholar in the Department of Electrical Engineering at the Rajasthan Technical University, Kota, India. She has been throughout university rank holder during her academics. 